\title{
Wayne G. Landis, Ruth M. Sofield, Ming-Ho Yu: Introduction to Environmental Toxicology and Molecular Substructures to Ecological Landscapes (5th Edn)
}

\section{Ken Jones ${ }^{1}$ \\ (c) Springer-Verlag GmbH Germany, part of Springer Nature 2018 \\ Bibliography \\ Introduction to Environmental Toxicology; Molecular Substructures to Ecological Landscapes $\left(5^{\text {th }} \mathrm{Edn}\right)$ Wayne G. Landis, Ruth M. Sofield, Ming-Ho Yu CRC Press, Boca Raton, FL, USA, 2017, pp 470 ISBN 978-1-4987-5044-8 GBP 90.00, USD 129.95}

The authors are fully active senior professors, all teaching this very complex subject. The almost staggering range of individual sciences involved range from the 'pure' sciences of chemistry, biology, and geology, through to ecology, microbiology, and statistics; a total of 22 separate subjects. This has resulted in 15 chapters of very concentrated reading. Surprisingly, radiochemistry is not listed. There are occasional references to radiological hazards, but the chapter on metals concentrates entirely on lead, cadmium, and mercury. It can only be concluded that the fly ash emitting from a coal-fired power plant producing 100 times more radiation than a nuclear power plant for the same amount of energy is not part of the teaching course. This omission seems strange when a declared aim of the course is "the findings of the field should have major implications for the making of environmental policy" - an obviously pious wish when reference is made to the current US energy policy, a policy highlighting "lower costs for hardworking Americans and (to) maximize the use of American resources, freeing us from dependence on foreign oil". The content and objectives of this book are far too scientific and sophisticated to have any relevance to the politicians who generate policy statements such as the one above.

Ken Jones

chromatographia@springer.com

1 Knutsford, UK

On the subjects presented, the book is an excellent nonjudgmental compilation of the most up-to-date toxicological environmental facts available. The chapter on emerging contaminants is particularly topical. The very latest cross-referenced academic papers on the important topic of microplastics in marine environments are analysed and rationally presented. The subject is current if only because David Attenborough, in the globally screened and superb Blue Planet II TV series, has used these data to conclude that the world's oceans are a 'toxic soup'-a useful stratagem, perhaps, to draw public attention to an ever-increasing possible problem, but regrettably wholly unscientific. The chapter on ecological risk assessment states it correctly. A definition of risk: "The probability of an effect on one or more specific endpoints due to specific stressor or stressors", in other words how often a change or changes in the environment will affect something of value to society, such as health, outdoor recreation, or the survival of an endangered species. The key word is probability, in the sense of a frequency distribution that has been estimated for the effects, good or bad, as a valued part of the ecological system. The hazard of a stressor requires the determination of its $\mathrm{LD}_{50}$ and mutagenicity, all sadly lacking to support the alarming statement "a toxic soup".

The principal problem facing the authors must have been how to make sense of this massive subject, if only because the subject content ranges from the macro to the micro. Very careful selection, of what is important and what is not must have been difficult; but by not creating a chapter on radioactivity as a major environmental pollutant a gap still remains to be filled. 